\title{
DNA Analysis and Recombination in X-linked Retinitis Pigmentosa
}

\author{
R. M. REDMOND,${ }^{1}$ C. A. GRAHAM,${ }^{2}$ I. W. CRAIG,${ }^{3}$ N. C. NEVIN,${ }^{2}$ \\ D. B. ARCHER ${ }^{1}$ \\ Belfast and Oxford
}

\begin{abstract}
Summary
$\mathrm{X}$-linked retinitis pigmentosa is a hereditary retinal degenerative disorder which has been localised to the proximal short arm of the $X$ chromosome. Recent evidence suggests that the disorder is heterogeneous with two possible loci for the disease mutation. DNA analysis on the family presented in this paper showed that the mutation mapped to the more telomeric locus (RP3), thus enabling two flanking polymorphic DNA probes (XJ1.1 and M27 $\beta$ ) to be used for the detection of female carriers in the family. In none of the carriers was a tapetal reflex (metallic sheen) observed.
\end{abstract}

The mechanism of expression of the mutant gene for $\mathrm{X}$-linked recessive retinitis pigmentosa (XLRP) is unknown. The progressive retinal degeneration commonly manifests with night-blindness in late childhood and severe peripheral and central visual field loss by the third or fourth decade of life. Cataract formation is frequent and some patients may have hearing loss. The diagnosis in an affected male is made by the typical 'bone-spicule' pigmentary changes in the retina and flattening of the electroretinogram (ERG). The sever-

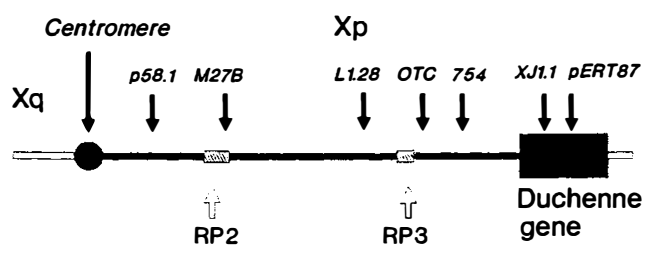

Fig. 1. Schematic map of probe loci and possible $X L R P$ loci on the short arm of the $X$ chromosome $(X p)$. ity, relatively early onset and lack of male-tomale transmission distinguish XLRP from autosomal dominant and recessive variants. Genetic counselling of females in XLRP families is difficult without a definitive test for carriers of the gene. Furthermore, there is controversy as to whether the disease gene has more than one locus on the X-chromosome short arm (genetic heterogeneity).

Clinical genetics has been revolutionised in recent years by the identification of DNA markers close to the genes for several common genetic disorders e.g. cystic fibrosis. These polymorphic markers are said to be linked to the disease gene and can be used to track the inheritance of the disease gene in families (gene tracking). Thus they provide an accurate means of carrier detection, presymptomatic and prenatal diagnosis. Several polymorphic DNA probes have now been mapped to the short arm (Xp) of the X-chromosome (Fig. 1). In 1984, L1.28 was shown to

${ }^{1}$ Queen's University Department Ophthalmology, Belfast. ${ }^{2}$ Queen's University Department Medical Genetics, Belfast. ${ }^{3}$ Genetics Laboratory, University of Oxford Department of Biochemistry.

Correspondence to: Mr. R. M. Redmond MSc. FCOphth. DO. Eye and Ear Clinic, Royal Victoria Hospital, Grosvenor Rd., Belfast, N.I. 


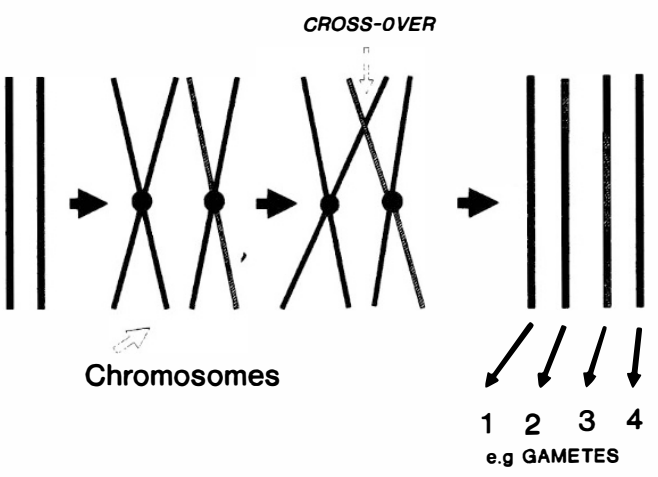

Fig. 2. Diagram illustrating a cross-over between the arms of paired homologous chromatids during meiosis.

be linked to the putative XLRP locus (RP2). ${ }^{1}$ The likely distance between the probe and the observed gene locus is five centiMorgans (cM), roughly equivalent to an intervening chain of five million nucleotide base pairs. This indicates that, during meiosis, there is a $5 \%$ chance of cross-over (recombination) between the probe recognition site and the disease loci on adjacent, paired homologous chromosomes (Fig. 2). The closer the loci for probe and gene, the less the likelihood of recombination. The linkage between $\mathrm{L} 1.28$ and RP2 placed the disease locus towards the centromeric end of Xp. Further linkage was reported with a centromere marker, ${ }^{2}$ suggesting that the RP2 locus was centromeric to L1.28.

However, the question of genetic heterogeneity was raised by reports of linkage between more distally placed Xp probes (OTC, 754 and $\mathrm{XJ} 1.1){ }^{3,4}$ In the single large pedigree studied by Nussbaum, ${ }^{3}$ the carrier females exhibited the tapetal reflex (one form of phenotypic heterogeneity), though only one of the four families studied by Musarella ${ }^{4}$ had this feature. The data from these OTC/754/ XJ1.1 linkage studies place the XLRP locus distal to L1.28, but proximal to the gene locus for Duchenne muscular dystrophy. Australian studies have suggested mapping of XLRP to an area between the probe loci for 754 and OTC. ${ }^{5}$ These alternative loci for the XLRP gene are shown as RP2 (proximal) and RP3 (distal) in Figure 1.

Mapping results are not precise as the distances between the probe and disease gene loci have $95 \%$ confidence limits that extend from 0 to $15 \mathrm{cM}$ for $\mathrm{L} 1.28$ and from 0.2 to $22 \mathrm{cM}$ for 754 . By comparison, the overall length of $\mathrm{Xp}$ can be roughly expressed as $90 \mathrm{cM}^{6}$

The genetic distribution of RP in Northern Ireland has been estimated at $31 \%$ autosomal recessive, $19 \%$ autosomal dominant, $3 \%$

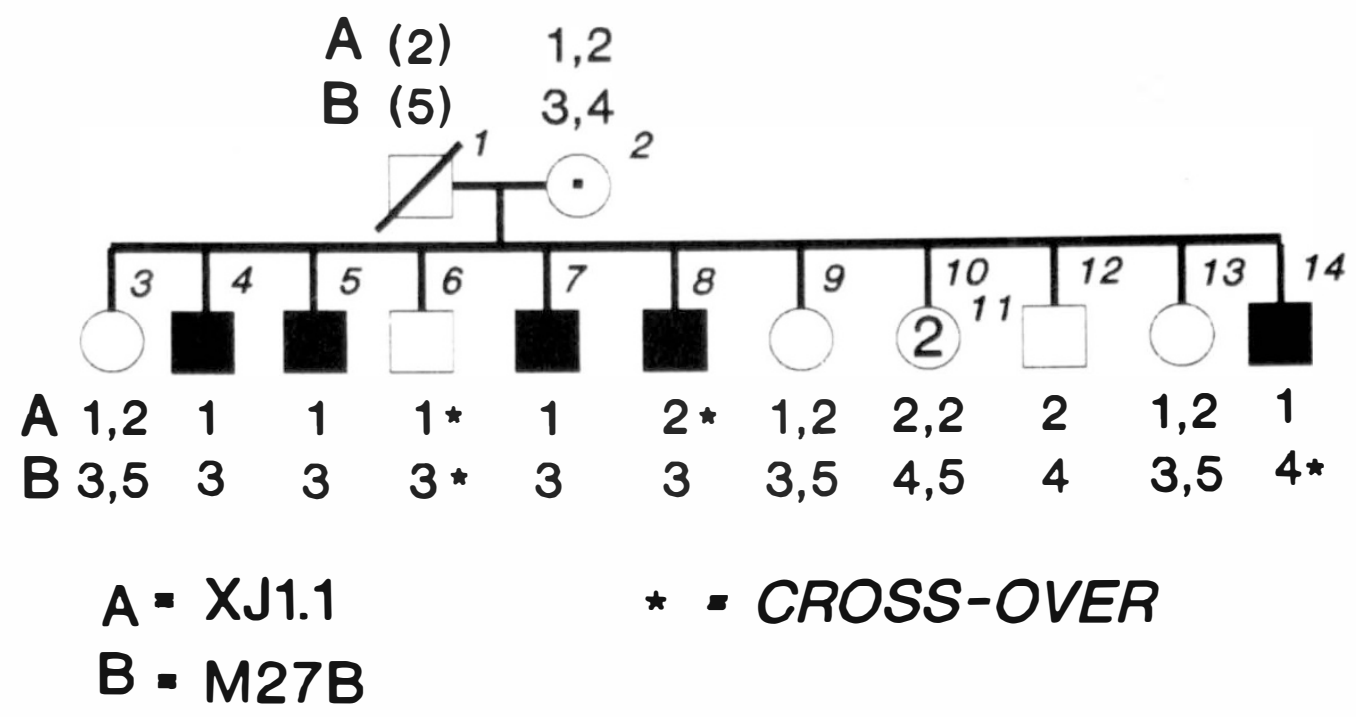

Fig. 3. Partial pedigree of a family with XLRP. Allele haplotypes are shown for each pedigree member. Allele numbers correspond to those shown in Figure 4. 


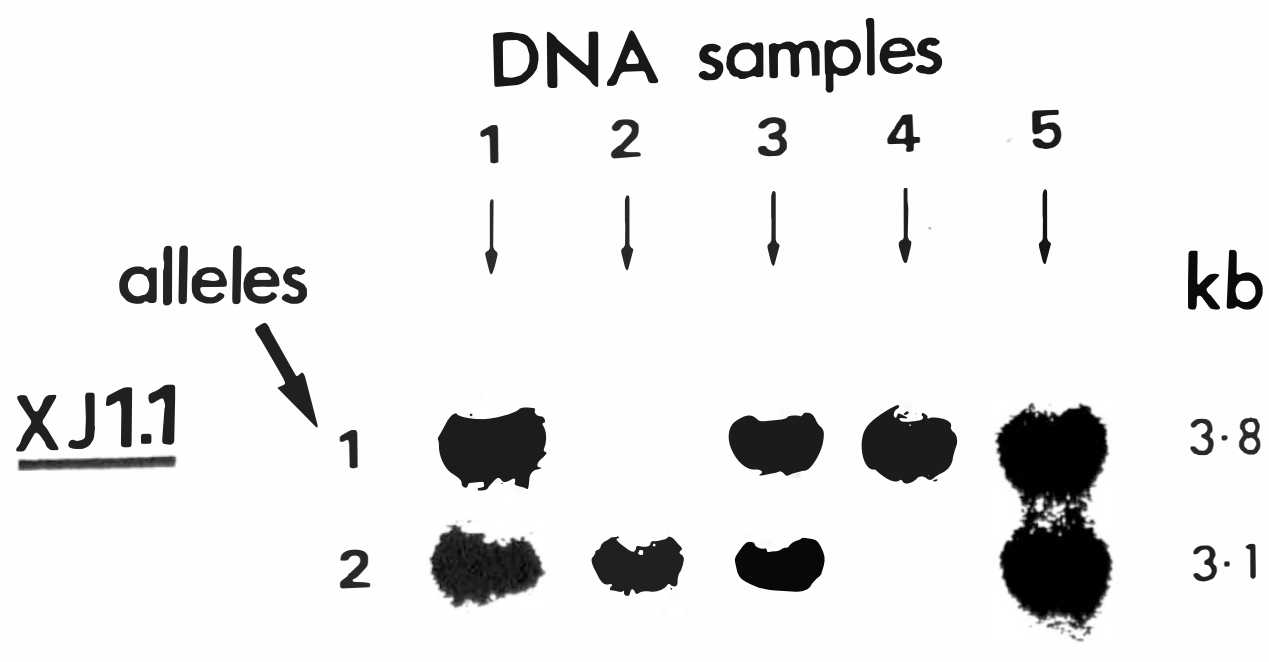

M27B

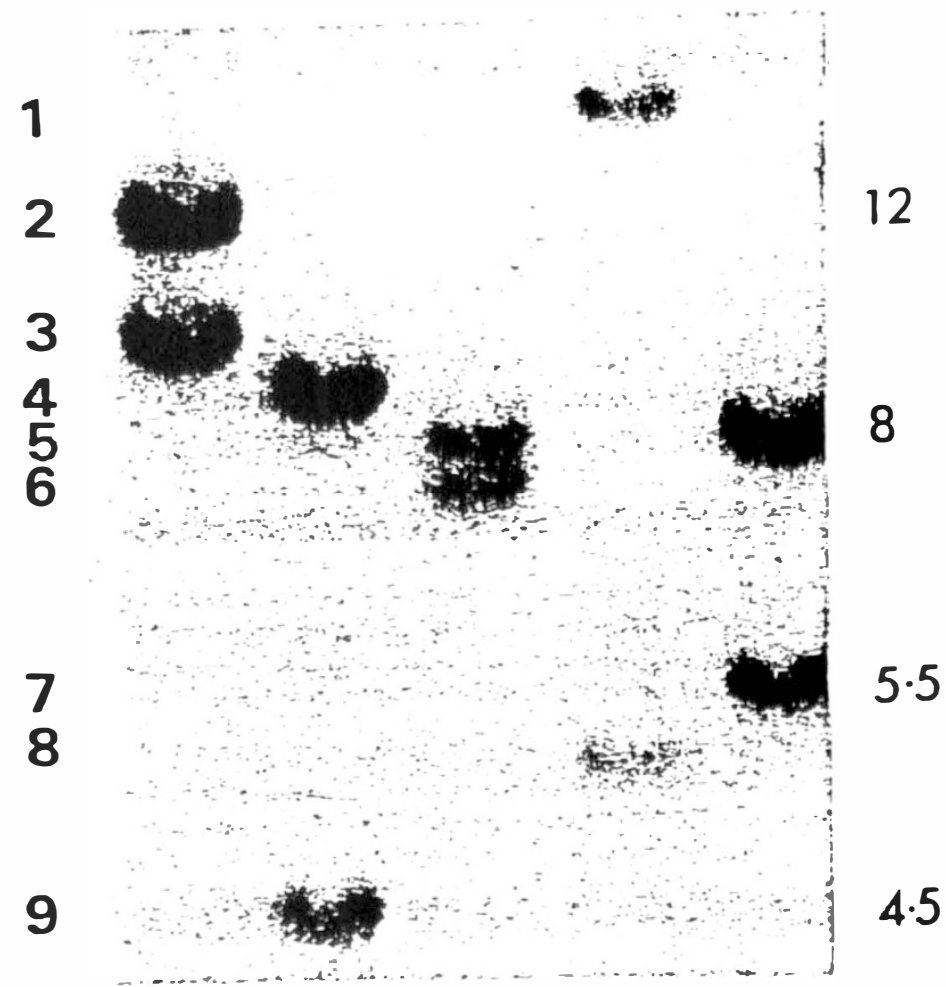

Fig. 4. Autoradiographs of representative Taqi/XJ1.1 and EcoRi/M27B restriction fragment length polymorphisms. 
Table I Restriction enzyme and DNA probe combinations used in this study

\begin{tabular}{lccc}
\hline Probe & Enzyme & Fragments $(\mathrm{kb})$ & Frequencies \\
\hline pERT87-15 & Taq1 & $3.1,3.3$ & $.67, .33$ \\
XJ1.1 & Taq1 & $3.8,3.1$ & $.28, .71$ \\
OTC & Msp1 & $6.6,6.2,5.1,4.4$ & $.61-.27$ \\
754 & Pst1 & 12,9 & $.55,-.45$ \\
L1.28 & Taq1 & 12,9 & $.68,-.32$ \\
M27B & EcoR1 & VNTR (multiple) & \\
p58.1 & Msp1 & $4,2.5$ & $.79, .21$ \\
\hline
\end{tabular}

X-linked and $47 \%$ simplex. ${ }^{7}$ We report on one XLRP family in Northern Ireland in which DNA linkage analysis with the probes M27 $\beta$ and XJ1.1 is informative, and in which the obligate and potential carriers of the XLRP gene do not exhibit a tapetal reflex.

\section{Materials and Methods}

The partial pedigree of the XLRP family is shown in Figure 3. There are five affected males, two unaffected males and five unaffected sisters in one generation. The mother (Fig. 3:2) has peripheral 'bone-spicule' retinopathy with good vision (suggesting the carrier phenotype) and the affected males had early onset night-blindness (before the age of ten years) and show posterior sub-capsular cataract formation. None of the boys in the third generation are older than eight years and it has not been possible accurately to diagnose carrier status in second generation females on a clinical or ERG basis, despite the eldest being 43 years old.

DNA was extracted from venous blood by a method based on that of Jeanpierre ${ }^{8}$ and the polymorphic DNA fragments resulting from restriction endonuclease digestion were separated by overnight electrophoresis in agarose gels. The DNA was then transferred from gel to nylon membrane by vacuum-blotting. Seven DNA probe/restriction enzyme combinations were used to identify polymorphisms (Table I).

$50 \mathrm{ng}$ probe aliquots were labelled with ${ }^{32} \mathrm{P}$-dCTP using the random hexanucleotide primer method of Feinberg and Vogelstein ${ }^{9}$ (Multiprime kit, Amersham Int.). The radioactive probe was separated from unincorporated nucleotides by passage through a Sephadex G50 column. The appropriate nylon membrane and labelled probe were incubated overnight in a formamide-based hybridisation buffer. Probe that had not hybridised to specific DNA recognition sites was washed off, and the membrane sandwiched between X-ray film (Fuji RX) for three to four days at $-70^{\circ} \mathrm{C}$.

\section{Results}

Polymorphic alleles detected by XJ1.1, pERT87.15 and M27 $\beta$ were informative in this family as key carriers were heterozygous. The allele patterns for XJ1.1 and -M27 $\beta$ are shown in Figure 4. pERT87.15 is similar to $\mathrm{XJ1.1}$. The distribution of these alleles in the family is shown in Figure 3.

Of the five affected males, four (Figs. 3: 4, 5, 7 and 14) have inherited the XJ1.1 allele 1, and four (Figs. 3: 4, 5, 7 and 8) have inherited allele 3 of M27 $\beta$, suggesting co-inheritance of these alleles and the disease gene. Single recombination events are shown in affected males 8 (XJ1.1 allele 2) and 14 (M27 $\beta$ allele 4).

Of the two unaffected males, one (12) has XJ1.1 allele 2 and M27 $\beta$ allele 4, suggesting that these alleles are inherited with the normal phenotype. His unaffected sibling (6) is unusual in that alleles 1 and 3 have been inherited, a pattern usually associated with the disease phenotype in this family. It is most likely that a 'double' cross-over has occurred in this unaffected male; distally between the disease locus and probe XJ1.1 and proximally between the disease locus and M27 $\beta$. The double cross-over has interrupted the linkage phase between the co-inheritance of alleles 1 ,

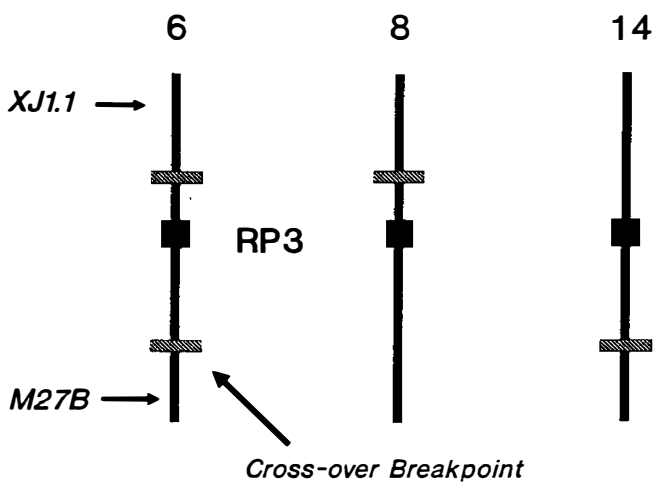

Fig. 5. Schematic maps for the most likely cross-over breakpoints for males 6,8 and 14 of the XLRP pedigree. 
Table II Representative carrier risk estimates for the $X L R P$ predigree

\begin{tabular}{llllll}
\hline Carriers (No.) & \multicolumn{1}{c}{3} & 9 & 10 & 11 & 13 \\
Pedigree tisk & 0.5 & 0.5 & 0.5 & 0.5 & 0.5 \\
Prọbe risk & 0.97 & 0.97 & 0.01 & 0.01 & 0.97 \\
\hline
\end{tabular}

3 and the XLRP gene. The most likely $\mathrm{X}$-chromosome cross-over break-points for males 6, 8 and 14 are shown in Figure 5.

The XJ1.1 and M27 $\beta$ probe results enabled computerised 3-point linkage analysis to be performed. The MLINK section of the program LINKAGE (version 3.5) was used with the recombination rates set to $10 \%$ and $20 \%$ for the XJ1.1 and M27 $\beta$ probes respectively. The approximate likelihood of the double cross-over described above is thus $2 \%$ $(0.2 \times 0.1=0.02)$ and its observation is a rare event. Carrier risk estimates calculated by MLINK are shown in Table II, and can be contrasted with the risk estimations previously derived from inspection of the pedigree only.

\section{Discussion}

On the basis of currently available linkage data, neither a proximal (RP2) nor a distal (RP3) site can be excluded as possible XLRP loci. Additional evidence for a distal locus has beendeduced from a male patient reported as having Duchenne muscular dystrophy, chronic granulomatous disease, the McLeod phenotype and XLRP. ${ }^{10}$ This patient had a chromosomal deletion in the region (predicted by linkage analyses) corresponding to the distal RP3 locus. Figure 1 illustrates the putative localisation of the loci in relation to known DNA markers.

The loci of XJ1.1 and M27 $\beta$ have been accurately mapped and it is known that M27 $\beta$ shows extensive recombination with some XLRP families and little or no recombination with others (Dr I. W. Craig, personal communication and Mettinger et al.). ${ }^{11}$ In this Northern Ireland family, the cross-overs observed suggest that the RP gene is located between XJ1.1 and M27 $\beta$. Unlike other reported families with possible distal RP loci, ${ }^{2,12}$ none of the females in this family exhibited a tapetal reflex. This finding suggests that the tapetal reflex may not have a strong association with inheritance of RP3.
Currently, OTC and M27 $\beta$ are the closest probes to the RP3 and RP2 loci respectively. $\mathrm{M} 27 \beta$ is informative in more than $95 \%$ of females, as it is multi-allelic, and it should be of great benefit in clarifying the issue of XLRP genetic heterogeneity. The use of M27 $\beta$ in this study enabled 3-point linkage analysis to be performed, so that more accurate genetic counselling can now be offered to this family, with high and low risk potential carriers being clearly distinguished. This had not been previously possible.

If XLRP genetic heterogeneity is confirmed (and assuming that there are only two loci), the significance will be as follows:-

(1) Linkage studies using current probes and linkage estimates will be applicable only to large individual families.

(2) Carrier risk estimation based on DNA analysis will need prior assignment of families to the RP2 or RP3 locus.

(3) When large families are classified as having either 'proximal' or 'distal' forms of XLRP, it may be possible to find clinical or electrophysiological markers that match this segregation.

(4) When clinical assessment is sufficiently refined to segregate 'proximal' and 'distal' families, it will then be possible to use appropriately-linked probes to perform carrier risk estimation in small families.

The relative proportion of families with either putative RP2 or RP3 loci is, as yet, unknown and a review of the current literature does not reveal sufficient data on which to base an estimate.

We wish to thank Mr. Brian Page for the identification of XLRP families in Northern Ireland and the provision of clinical data.

\section{References}

${ }^{1}$ Bhattacharya SS, Wright AF, Clayton JF, Price WH, Phillips CI, McKeown CME, Jay M, Bird AC, Pearson PL, Southern EM and Evans HJ: Close genetic linkage between $\mathrm{X}$-linked retinitis pigmentosa and a restriction fragment length polymorphism identified by recombinant DNA probe L1.28. Nature 1984, 309: 253-5.

${ }^{2}$ Friedrich U, Warburg M, Wieacker P, Wienker TF, Gal A, Ropers HH: X-linked retinitis pigmentosa: linkage with the centromere and a cloned DNA sequence from the proximal short arm of the X chromosome. Hum Genet 1985, 71: 93-9.

${ }^{3}$ Nussbaum RL, Lewis RA, Lesko JG, Ferrel R: Mapping X-linked ophthalmic diseases: II. Link- 
age relationship of $\mathrm{X}$-linked retinitis pigmentosa to $\mathrm{X}$ chromosomal short arm markers. Hum Genet 1985, 70: 45-50.

${ }^{4}$ Musarella MA, Burghes A, Anson-Cartwright L, Mahtani MM, Argonza R, Tsui L-C, Worton R: Localisation of the gene for $\mathrm{X}$-linked recessive type of retinitis pigmentosa (XLRP) to Xp21 by linkage analysis. Am J Hum Genet 1988, 43: 484-94.

${ }^{5}$ Chen JD, Halliday F, Serravalle S, Denton M: Localisation of the $X$-linked retinitis pigmentosa locus between DXS7 and DXS84 in a family showing tapetal reflex in heterozygotes. Ophthalmic Paediatr Genet 1988, 9: 143-7.

${ }^{6}$ Ropers H-H, Wieacker P, Wienker TF, Davies K, Williamson R: On the genetic length of the short arm of the human X chromosome. Hum Genet 1983, 65: 53-55.

${ }^{7}$ Page B. MD Thesis: Queen's University of Belfast. 1988.
${ }^{8}$ Jeanpierre M: A rapid method for the purification of DNA from blood. Nuc Acid Res 1987, 15: 9611.

${ }^{9}$ Feinberg AP and Vogelstein B: A technique for radiolabelling DNA restriction endonuclease fragments to high specific activity. Anal Biochem 1983, 132: 6-13.

${ }^{10}$ Francke U: et al. Minor Xp21 chromosome deletion in a male associated with expression of Duchenne muscular dystrophy, chronic granulomatous disease, retinitis pigmentosa and McLeod syndrome. Am J Hum Genet 1985, 37: 250-67.

${ }^{11}$ Meitinger T, Fraser NA, Lorenz B, Zrenner E, Murken J, Craig IW: Linkage of X-linked retinitis pigmentosa to the hypervariable DNA marker M27 $\beta$ (DXS255). Hum Genet 1989, 81: 283-6.

${ }^{12}$ Denton MJ, Chen JD, Serravalle S, Colley P, Halliday FB, Donald J: Analysis of linkage relationships of $\mathrm{X}$-linked retinitis pigmentosa with the following Xp loci: L1.28, OTC, 754, XJ-1.1, pERT87 and C7. Hum Genet 1988, 78: 60-4. 